\title{
THE INTEGRATION OF COMPUTER-MEDIATED COMMUNICATION AND INFORMATION TECHNOLOGIES IN HIGHER EDUCATION
}

\author{
Dr. Mohammad Othman ALNais \\ Hail College of Technology, P.O. Box 1690, Hail, Kingdom of Saudi Arabia. \\ Email: malnais2002@yahoo.com
}

\begin{abstract}
Universities and colleges offer students the opportunity to grow intellectually and creatively through the advanced study of science, engineering and literature. As modern workforces require well-motivated individuals with the skills and adaptability to meet the demands of an ever more competitive world market for quality products, the government of the Kingdom of Saudi Arabia (KSA) wants to see a successful and inclusive society, with a competitive economy built on the talents and skills of all.

The idea that technology is changing the way we work and learn has become a constant refrain in contemporary society. Thus, universities and higher colleges look to modern technologies to help solve problems that have inhibited learning in the past. Another challenge to institutions, of higher education with regard to professional development in areas of technology is the mere fact that students of tomorrow will be more dependent on technology skills than the students of today.

Taking up the idea that educational technologies have the potential to alter how universities and higher colleges are run and how students learn. This paper addresses how to encourage widespread effective use of new technologies, in teaching, learning and research in all educational institutions and all subjects to ensure that students are able to use new technologies to enhance their learning and prepare for working life.
\end{abstract}

\section{INTRODUCTION}

The habit of learning is the sign of a civilized human being. However, we must recognize that global changes in the last decade have been so prodigious that 
formal education has not yet been able to adequately cope with them.

Educational sciences made efforts to use technology of industrial society for their own purposes, this technology eminently mechanical and electrical. At the end of this century education has had to incorporate powerful technological tools provided by new electronic, magnetic and optical systems. The contrast between the two types of technological implementation is revealing. Entering the 21 st century, we embark on an era of historic change in which the new communication, computing and information technologies (IT) have the potential to renovate education and society [1] fully for the betterment of humankind. IT has the potential to solve many problems, it can change the roles of students and faculties, facilitate more learner-centered, personalized education, and expand the scope and content of the curriculum [2,3].

Changes in technologies change what people can do in life, and significantly alter the possibilities open to people thinking. They change five conditions limiting the value and power of ideas in human activity. New communications tech-nologies facilitate the production and reproductions of ideas; they expand the storage of ideas and make their retrieval faster and more adaptable to the constraints of situation, time, and place; they improve the transmission of ideas, expand selection among them, and strengthen the human capacity to use ideas to process information intelligently. Thus, formal education must adopt a new pedagogy, oriented not to text-bound subject matters, but to dynamic operational skills and collaborative modes of inter-disciplinary thinking. Students will require new languages to interact with information systems. They will require a multi-model literacy combining video, audio, graphics, animation, and simulation, along the text. They will require a more refined ability to handle the language of inquiry, knowing where and how to formulate and frame their questions, to obtain useful information, and to create empowering ideas. They will require the capacity to produce new knowledge by discovering, selecting, and combining previously unrelated data in novel ways. Education will increasingly be judged, not only by what the well instructed prove to know, but more fully by what people are empowered to do in fulfilling their lives and contributing to the greater social good. Knowledge is power, and in an intellectual democracy it must be power for all universities and in all educational institutions. Hence, an education for the $21^{\text {st }}$ century must provide people with mastery of the intellectual and technical skills necessary to participate to their field potential. And Just as IT has brought about the convergence of computing and communications, so, we believe, can bring technology and education close together. Today's students will thus live their entire life in a technological world. And as technology plays a major role in reducing professional pressure on lecturers and increasing the efficiency of student comprehension [4]." According to Holsinger [5], a single topic, expanded with graphics, text, and video, can help a student grasp difficult subjects. By using a large screen projector with an interactive software program, lecturers may. elicit questions from students, and respond with a variety of media to illustrate and explain difficult concepts. Universities will not survive such uncontrollable expenditures. without any visible improvement in either the content or quality of education [6] and must thus get serious about preparing them for the world [7]. 
This paper fosters the creation and dissemination of knowledge about the use of information technology and focus on:

- How to advance the role of computers and other information technologies in education and society, and on the new education needed in the near future in the KSA, and

- How all people and especially students can use IT in its various forms in the field of education to enable themselves to fulfill their hopes and potentials.

\section{INTEGRATION OF NEW TECHNOLOGIES INTO EDUCATIONAL AND RESEARCH FUNCTIONS}

Educational communication and collaboration are becoming regional and even global. At the same time the effectiveness of university and industry education must be improved, and continuing education expanded. The challenge is to find the best ways to exploit technology to enhance the creativity, collaboration, and communication that will be at the heart of the new education for the next century.

In order to expand educational opportunity and achievement. University should be engaged in a number of large-scale regard projects intended to develop, test, and implement effective use of new technologies. Hence, there is the essence of the university's strategy for significant change in education: use technology to enable educators to achieve radial improvements in successful institutions. and thus, KSA is committed to continuing to help lecturers and engineers in all educational institutions integrate new technologies into their own educational and research functions by applying the experiences gained through on-going projects to their requirements.

Such new technologies are:

- the internet

- $\quad$ multimedia

- communication satellites

- $\quad$ artificial intelligence and networked learning

- digital imaging media technology

- computer supported collaborative learning

- distance education

- digital education

It is well known that the mission of the university should be a center of excellence in the development and use of new technology in teaching, learning and research and to reach these goals university should:

1 - initiate projects in the use and development of technology-based methods in teaching, learning and research.

2- ensure that university is provided with rapid access to these developments and that its own use of technology-based methods in teaching, learning and research is fully advantaged by the work of IT engineers and researchers.

3- assist the staff of the university, in collaboration with other support services, in the acquisition, development and delivery of teaching, learning and research materials using technology-based methods.

That is the mission of the university, and there is a worthy mission for lecturers, but to fulfill it, they too must master the possibilities of the new technologies [8.9] and adopt a new pedagogy, oriented not to text-bound 
subject matters, but to dynamic operational skills and collaborative modes of inter-disciplinary thinking.

\section{DISTANCE EDUCATION}

At its most basic level, distance education takes place when a lecturer and student(s) are separated by physical distance, and technology (i.e., voice, video, data, and print), often in concert with face-to-face communication, is used to bridge the instructional gap. These types of programs can provide adults with a second chance at an educational institution, teach those disadvantaged by limited time, distance or physical disability and update the knowledge base of workers at their places of employment.

Teaching and studying at a distance can be as effective as traditional instruction when the method and technologies used are appropriate to the instructional tasks, when there is student-to-student interaction, and when there is timely teacher-to-student feedback [10]. Thus, from a promotion point and also to update knowledge base of workers in all sectors (industry, commerce, economy etc...), the KSA has to be aware of this important method of teaching [11], and it is suggestible to start introducing this type of education.

\section{DIGITAL EDUCATION}

Digital education has begun to spread learning outside schools, colleges and universities taking it into homes and workplaces as a result of the growing use of information technology.

The overall goals of the digital imaging and media technology program are:

- To utilize digital methods to preserve and to make accessible fragile and under-utilized visual resources;

- To promote the use of digital media throughout the university and education institutions; and

- To conduct research that advances the creation and use of these resources.

The fielding case study provides some indicators of individual characteristics for achieving success for both students and teachers in these digital classrooms. Students who are most likely to succeed are described as;

-People who enjoy working alone

-People who can structure and manage time well

- Accomplished, busy professionals;

- Students with superior verbal ability;

- Risk-taking, creative problem solvers;

- Individuals committed to peers and the group process; and

- People who are comfortable with asynchronous rhythms.

Research has shown that university-level students participating in distance learning are typically older and married, have children and are often juggling their school, work and family responsibilities [12].

Likewise, successful faculty members able to teach well and enjoy working in the digital networked learning environment are described as;

- Serious, lifelong learners; 
- Teachers favoring experimental and collaborative styles;

- Those who enjoy up-front conceptual work;

- Skilled group process facilitators;

- Teachers who make expectations explicit;

- Those who construct evaluation/ assessment schemes;

- Providers of detailed, developmental feedback; and

- $\quad$ People willing to give feedback at frequent intervals.

\section{COMPUTERS IN EDUCATION}

The impact of technology in the computer age has been of such a magnitude that many teaching resources are disappearing, being substituted by electronic equivalents. This is the case of the overhead projector. In recent years this has become a very popular system to a certain extent complementing and replacing the blackboard. Overhead projection techniques were in fact a significant advance for teachers as in the first place, teachers can continue to talk without turning their backs on the class, while writing or drawing on the slide. Even more important, it facilitates the organization of the courses, as the transparent sheets act as an ordered collection of notes. Many of these interesting educational uses of slides have been preserved and perfected in modern systems of digital presentation. These are shown on computer screens and can be projected onto much larger screens, and can be modified in a number of ways using electronic pointers and sensitive buttons. One currently fashionable technology is the use of overhead projectors with liquid crystal displays connected to computers. In these cases electronic pages generated by computer replace individual slides, which are presented in memory as just another file.

Projection of slides and audio-visual material: This technology enable the presentation of collections of many images ordered sequentially which can be remotely controlled either manually or using pre-programmed automated circuits. However, today a new generation of audio-visual resources has appeared, multimedia based on the technology of digital projectors and compact discs (CD-ROMs) which have opened up a new field with an impact on education that could be incalculable CD-ROMs can hold thousands of photographs and images in movement, as well as sounds. Their cost is minimal when compared to the information contained on previous audio-visual systems. Computer technology is rapidly advancing. Innovations are constantly emerging, while related costs drop. And these developments have made the computer a dynamic force in education, and it can be used in four different applications:

1- Computer Assisted Instruction (CAI): Uses the computer as a selfcontained teaching machine to present discrete lessons to achieve specific but limited educational objectives (tutorial, problem solving and simulations and games).

2- Computer Managed Instruction (CMI): Uses the computer's branching storage, and retrieval capabilities to organize instruction and track student records and progress.

3- Computer Mediated Communication (CMC): Describes computer applications that facilitate communication (Electronic mail. computer conferencing and electronic bulletin boards) 
4- Computer-Based Multimedia (CBM): Integrate various voice, video, and computer technologies into a single easily accessible delivery.

Student access to modern computer-aided decision support system is this, an obvious key to learning about new information technologies. However, what is not so obvious is the lack of available realistic process examples and data as a basis for learning how to effectively use information technology tools and explore their application to process improvement. If experience is to be provided on process improvement within the engineering curriculum, processoperating data must be available for students to analyze, develop models of process behavior, and design and test improvement concepts.

Universities are the center of excellence in the development and use of new technologies, their objectives thus, should relay on continuing curriculum improvement program that synergistically seeks solutions to the problems of strengthening industrial and economic competitiveness as a basis for achieving essential education delivery system reforms. To reach these objectives, it is proposed that universities follow a four-pronged strategic plan:

1- Create a computer-aided process improvement laboratory to provide an open instruction/learning environment for the formulation and solution of process improvement concepts.

2- Develop educational modules to infuse curricula with activities and exercises that require students to formulate meaningful questions and find appropriate answers.

3- Create and utilize a networked electronic library to archive, disseminate, and share the laboratory resources and instruction modules.

4- Implement a continuous process for evaluation, analysis and improvement of the laboratory and education modules is an integral component of the development effort.

\section{CONFOR'T LEVEL WITH COMPUTERS}

Students will require a new way of learning/instruction via computermediated-communication technologies for century, and should make an effort to continue seeking the best possible way to exploit technologies for enhancing learning, and as computer-aided learning tool, simultaneously displays a visual-representation of an interesting, real, environment, and a map view of that same terrain, in order expand the bounds of what can be learned in a class Students should:

1- run the applications the need to use a computer

2- create, save and manage files on their computers

3- know how to install software on their computer if they need to.

\section{DIGITAL IMAGING}

The digital imaging and media technology initiative has a combined focus on technical imaging and visual information access and retrieval, enabling us to develop optimal methods for creating and providing access to experimental electronic files of visual information, as well as studying its use in the digital environment. Thus, traditional limitations are changing. Nearly all the data 
acquired in working laboratories is fast becoming digitized and it moves rapidly across networks from lab to lab and researcher to researcher.'More and more, scholars capture, observe, analyze, and interpret all this material with computer-based tools, many of which are not difficult to use. The emerging information infrastructure can transport all these observations, measurements, collections, and models to virtually anyone anywhere, along with control over powerful tools of rendering, calculation, comparison, selection, organization, and expression.

\section{INTERNET ACCESS}

The internet and the World Wide Web, (WWW) which are the technologies now in the forefront of efforts to improve education, differ markedly from earlier teaching media. They enable users to store, access, display and transmit information in ways never before possible. The Web's multimedia communication [13] and interactive capabilities greatly facilitate the creation of environments for distributed learning and collaborative research and development. The Internet has been variously characterized as an efficient means of communication [14].

The WWW provides Internet users with a uniform and convenient means of accessing the wide variety of resources (pictures, text, data, sound, video) available on the Internet.

Universities in the KSA have to empower the students by providing an ondemand Internet skills course. This course should use the most current Internet technologies.

Lecturers will be needed more than ever to help students navigating the network to develop a critical sense personal responsibility and universal values and to access essential information resources. These skills will be valuable not only for formal education, but as life-long learning skills that will allow success as information technology evolves. Thus, universities should:

- Implement a model-on demand delivery internet course taking advantage of the newest internet technology;

Train students to use Internet tools to locate, acquire, exchange, utilize and create new information equip students with the skills required to succeed in the electronic information environment. Navigate effectively and access essential information resources, and should understand and be able to employ search techniques on a variety of search engines and in a variety of data sources.

- Initiate a collaborative interactive learning environment that eliminate time, distance and location barriers;

Cooperatively create an electronic reference tool to be accessible in the whole kingdom.

There are two kinds of information on the Internet that can be used in teaching: what is there already, and what you put there ourselves. It takes a little exploring to find what is out there and filter it for classroom use, and it takes a little work to prepare materials ourselves, but both can be very rewarding. There are several ways lecturers can enhance their communication with students: 
- Make their e-mail address known to students, encourage them to use it, and be sure to respond in a manner timely enough for them to get used to. The question that the student though was not quite important enough to ask gets asked and answered.

- Get students e-mail addresses from them and send them messages, either individually or as a group, you can set up a e-mail "list", every time you send mail to one student, a copy of that message would go to every student whose address is on the list.

- The logical way to use such list is in fact to let the students communicate with you and with each other that way. Encourage posting of questions to that list; post important information to yourself (advice on how to study, updates assignments and their solutions).

Students should also be able to:

1- access internet email and World Wide Web (WWW) at least twice or three times a week

2- if the do not have their own computer, they can get to the university to use the computer labs or arrange to use some other computer at least twice a week.

\section{INTERNET SKILLS}

Students should:

1- have an email address

2- know how to send and receive email messages

3- know how to attach a file to an email message

4- know how to paste text from a word processor into an email message

5- know how to receive a file attachment from an incoming email message.

6- Know:

how to reach (get) diverse institutions

how to produce a web site

how to reach a site

how to find publications

how to access to the university library's collection, and to perform research with collections and users to determine the best methods for doing so.

\section{USING THE INTERNET TO ENHANCE CONTENT LEARNING}

It is one thing for a teacher to get connected with the Internet and learn to use it [15]. The Internet is simply another tool to use in the learning process, and focus on methods to integrate its possibilities for accessing information and building information literacy.

The general intention of KSA has from the beginning been in alignment with oft-started goals of university technology programs. To encourage the effective and appropriate use of technology in educational institutions in order to improve the educational experience of teachers and students.

Encourage students and teachers to work together in finding novel ways to integrate new technologies into the learning day. In this context, technology is used as: 
1- A replacement for traditional materials such as reference materials, textbooks or analog equipment.

2- A means to augment traditional practices, as with illustrations, charts interactive multimedia, and dynamic information.

3- A tool to promote communications within and between classrooms in support of collaboration or research.

4- An access point, via the internet and CD-ROMs, to the work and ideas of people across the planet and in many languages

5- A barrier-free, multicultural onramp for students regardless of geography, gender, race, language, physical challenge or economic status.

For technology to be effective in the classroom, teachers are being asked to examine their traditional teaching methods for ways in which technology can have a positive impact when integrated into their classrooms. Students are asked to apply their imaginations and energy towards appropriate use of technology in the completion of their work.

Where possible, the best way to include technology in teaching is to align it with existing curriculum, reasonable expectation and identified needs. Thus, weak use of technology often involves activities associated with:

1- Computer time as a reward system for desired behavioral or academic outcomes.

2- Rote drill or memorization practice.

3- Personal computers used as word processors only, or to teach keyboarding.

4- Internet access used for entertainment, without reference to a valuable lesson or product.

\section{PREPARATORY YEAR EDUCATION}

Universities should design a program to assist high school graduates in upgrading their qualifications to meet college and university requirements and to complete university transfer or college credits. The preparatory year will thus be specifically designed to provide students with opportunities to improve their academic, computer and study skills in preparation for university courses and the world of work. Thus, students should spend an academic year on a course designed to answer the needs of the students and the needs of tomorrow's world. The individual needs of students should be assessed and identified by lecturers who will assist them to develop their individual educational plan, and this assistance in my view should consist of a combination of the following components:

- Counseling

- Orientation week

- Preparation for supplementary exams in high secondary school courses

- Preparatory work in the subject areas that are common to the majority of universities such as : mathematics, physics, English and computer applications

- Scheduled meetings with the faculty advisor

Standardized tests, recommendations, and student performance are important admissions considerations. However, the primary factor is the content of academic programs, the depth, breadth, and rigor of study programs that 
prepare students for future academic opportunities. Thus, during the preparatory year, students should be given an opportunity to obtain the level required for regular study at the university.

\section{INFORMATION TECHNOLOGY IN THE PREPARATORY YEAR}

There is a lot of interest in the use of technology in education these days. The use of new technologies such as multimedia is an important aspect of education in the new information age. Such technologies allow students and lecturers to access vast amounts of information quickly and efficiently and thus could provide better learning activities, and maximize educational productivity. KSA universities could take this advantage and provide support to students' access to current information technologies including computers, appropriate software, CD-ROM players, networking, multimedia, distance learning and the Internet. Through access to the World Wide Web (WWW), students will discover new approaches to global education Thus in preparatory program, KSA universities should:

- Create high quality multimedia production via improved computer hardware and software

- Improve vocal instruction utilizing video and audio equipment

- Improve instruction in speech-language utilizing integrated computerized technology

- Improve instruction of underprepared students via university preparatory academic.

\section{METHODS FOR SELECTION OF SUJECTS AREAS}

Although KSA universities offer a preparation courses targeted at improving deficiencies in specific subject areas. There is a little agreement between universities on what should be contained in these courses, or even a uniform approach as to the determination of the need for these courses. Methods for selection of subject areas for preparatory programs are thus needed, and the selection of such subjects should be first based on the targeting of subjects with large rates of failure, because this seems to be a logical choice for bridging attention. The reasons for the large failure rates may have been caused by deficiencies in the level of students' knowledge on entry however; the reason may also be due to other factors such as:

- The lacking subject material

- Poor lecture techniques

- Badly constructed assessment documents.

From the above factors, KSA universities should adopt procedures to identifying subject areas for preparatory courses. Some proposed procedures are:

- through verbal consultation with lecturers to identifying weak areas of students.

- questionnaire administrated to lecturers

- questionnaire administrated to students

- failure rates in specific courses

- by demand from staff

- by student demand. 
By adopting a best selection method, the universities will make the transition smoother and will allow students to get on with achieving their real desire in further study.

\section{CONCLUSIONS}

No nation holds a monopoly on technology, or on the uses of technology in education. The great variety of ideas and initiatives in this field worldwide offer a valuable range of resources for researchers, teachers, and administrators engaged in the field of education.

- Information Communications technology (ICT) should be taught as a national curriculum subject, or built into other courses. A great deal of emphasis should be placed on its use in all subjects to ensure that students are able to use new technologies to enhance their learning and prepare for working life.

- An (information) strategy will need to embrace competition and collaboration in bringing about change. Such strategies should cover information resources, the facilitation of staff/student communication, the development (purchase or production) of learning and teaching materials and other content, and the development of effective management information systems in an integrated manner.

- Clearly, advanced information technologies enhance communication and collaboration. It is the intention of this server to take full advantage of these capabilities, to inform the higher education community and to solicit their participation in the development of the technology and distance education initiative.

- Education must respond to whatever conditions exist, and the fact is, the world is becoming more global. Thus, KSA universities curriculum should be focusing on a global approach preparing students to manoeuvre intelligently and successfully in a fast-paced, ever changing world.

- Plans should focus on the student, the classroom, faculty roles, and learning outcomes, rather than on the technology itself. The danger in not having clear goals and pedagogical objectives is that the technology will be acquired but not truly integrated into the teaching, learning, and research of the university. Universities using information technology in their classes need to establish goals too. It is advisable to empower the students in KSA by providing an ondemand Internet skills course, which will use the most current Internet technologies to teach students to use Internet tools, and faculties should express growing interest in teaching via the Internet among university faculty members.

- Finally, a continuing challenge for educational institutions as they redefine their roles is to prepare students and faculties to be lifelong learners. In the age of technology this means universities should be moving from providing information to providing opportunities and skills required for learning, such as problem solving, critical analysis and adaptability of current knowledge to new situation. 


\section{REFERENCES}

[1] J. Taffin, and L. Rajasingham, In search of the virtual class: Education in an information society. New York, Routledge, 1995.

[2] J. Frand, 1996 thirteenth survey of business school computing usage. Los Angeles: Anderson computing services, Anderson Graduate School of Management at UCLA, 1996.

[3] K.C. Green. Compus Computing 1996. The seventh national survey of desktop computing and information technology in American Higher Education. Claremont, CA: Campus Computing Project, 1996.

[4] Carvin, Andy "Exploring Technology and school reform" Ed Web Home Page

http://k12.cnidr.org.90/school/reform

[5] E. Holsinger. How multimedia works. Emeryville, CA: Ziff-Daus Press, 1994.

[6] E. Flom. STARS- Student tracking and retention for success: Teacher and student improvement through technology. National title III conference, Washington D.C.: Brevard Community College, FI.

[7] D. Topper. Strengthening institutions: Title III Grant proposal (Award No. P031A40036). Baytown, TX. Lee College, 1994.

[8] L. Harasim, S.R. Hiltz, L. Teles, and M. Turoff, Learning networks: A field guides to teaching and learning online. Cambridge, MA: The MIT Press, 1995.

[9] M.J. Marquard, and G. Kearsley, Technology-based learning: Maximizing human performance and corporate success. Washington D.C: CRC Press, 1998.

[10] Badrul Khan, Karen Murphy and Cynthia Lopez " Models for collaborative teaching/learning at a distance" Published in Technology and Teacher Educational Annual, 1996, pp. 600-602.

[11] B. Holmberg, Theory and practice of distance education. New York Rout Ledge, 1989.

[12] W.E. Souder, " the effectiveness of traditional Vs satellite delivery of the management of technology master's degree programs", the American journal of distance education, 7191 0, 1994, pp.37-53.

[13] Z.L Berge, and M.P. Collins, (Eds.)," Computer mediated communication and the online classroom. Vol. II: Higher Education. Cresskill, NJ: Hampton Press, 1995.

[14] Sproull, Lee and Sra Kiesel, mediated instruction employing the Internet and the World Wide Web.er connections: New ways of working in the networked organization, Cambridge, MA: MIT Press, 1995.

[15] The busy educator's guide to the World Wide Web by marjan Glavac http:/205.252.192.2/wmc/biblio/books.html.marjan@glavac.com 


\section{إدماج الحاسب الآلي التوسطي وتثقية المعلومات في التعليم العالمي \\ لـ. محمد عثمان النعيس}

الكلية التقنية بحائل ، ص. ب ـ 971 ا، حائل ، المسكة العربية السعودية

تقـدم الجامعات والكليات للطلاب الفرصة للنمو الفكري والإبداعي عبر الار اسات

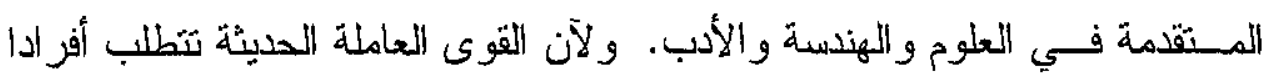

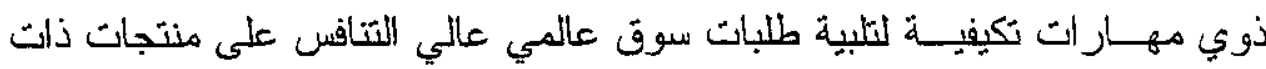

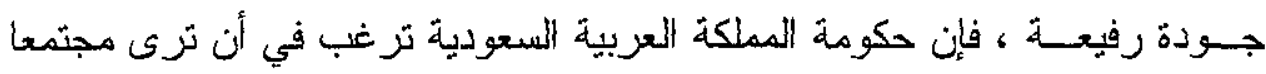

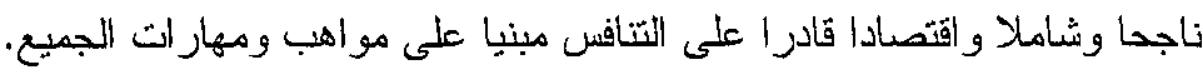

أصسبحت التكنولوجيا في المجتمع المعاصر ضرورية لتغير أسلوب عملنا ونعلهنا.

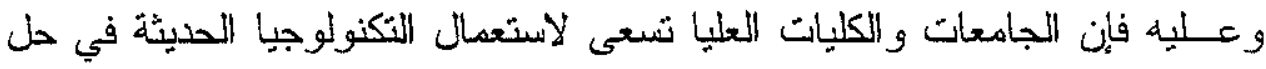

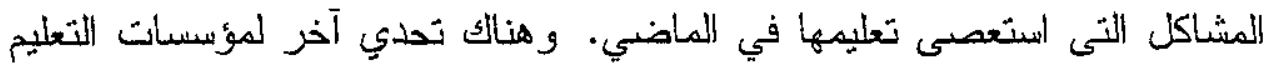

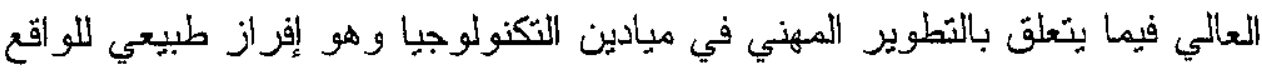

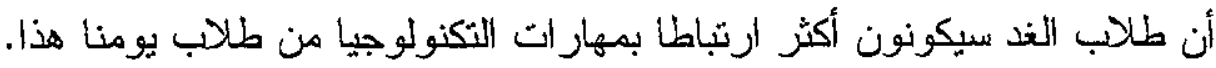

إيمانا بأهمية المعلومة وضرورة الحصول عليها وقت طلبها وانطلاقا من أن خطة

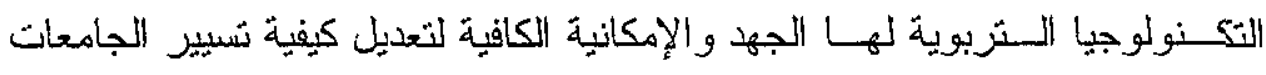

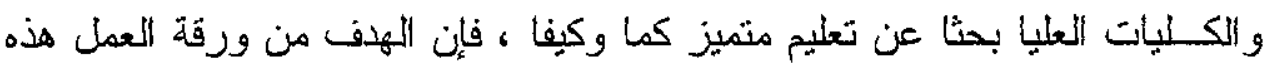

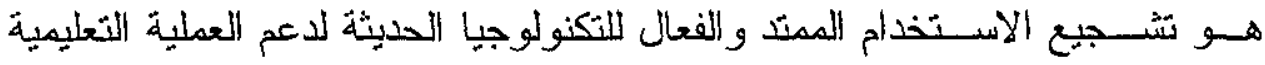
و البحسثية في كل المؤسسات التزبوية وفي كل التخصصات للتأكد من تتمية معرفة

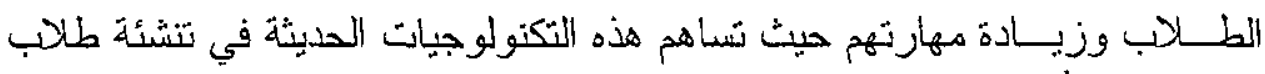

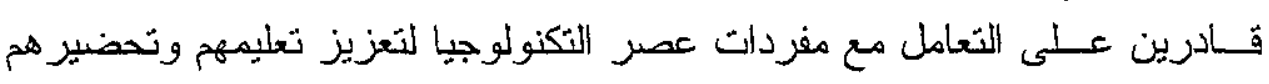

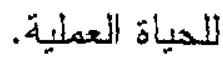

أصسبحت التكنولوجيا في المجتمع المعاصر ضرورية لتغير أسلوب عملنا وتعلمنا.

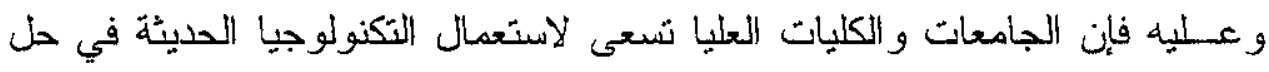

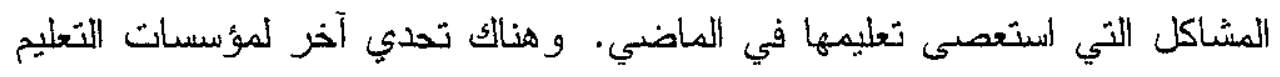

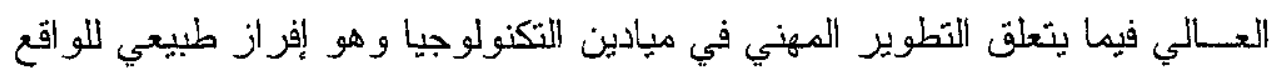

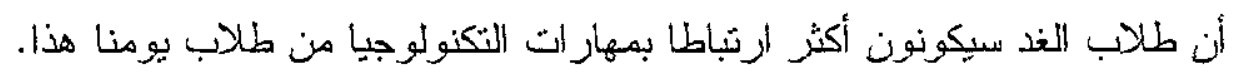


إيمانا بأهمية المعلومة وضرورة العصول عليها وقت طلبها وانطلاقا من أن خطة

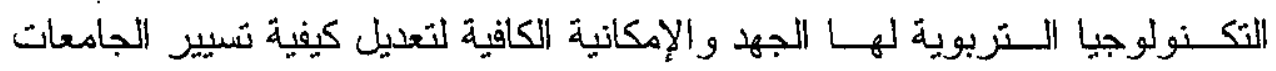

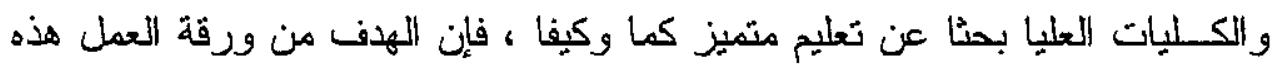

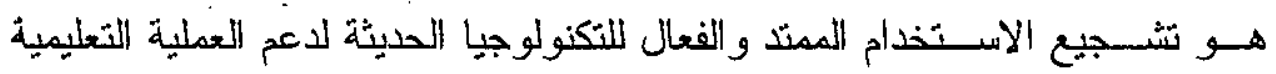

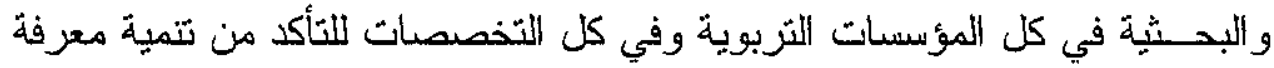

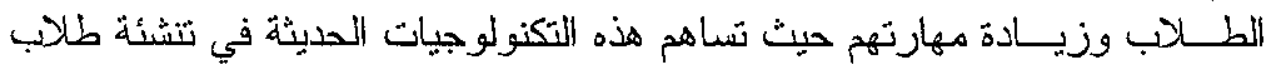

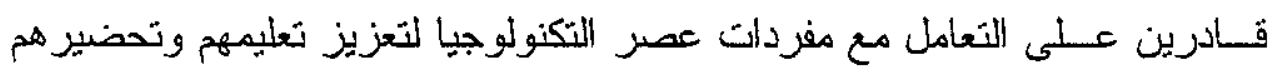
للحياة العملية. 